\title{
Telemedicine Among Oral Medicine Practitioners During COVID-19 Pandemic and Its Future Impact on the Specialty
}

\author{
Maha Ali Al Mohaya (D) \\ Mansour M Almaziad ${ }^{2}$ \\ Khalid A Al-Hamad (iD ${ }^{3}$ \\ Mohammad Mustafa (iD) \\ 'Oral Medicine \& Special Care Dentistry, \\ Prince Sultan Military Medical City, \\ Riyadh, Saudi Arabia; ${ }^{2}$ Oral Medicine and \\ Pathology, Prince Sultan Military Medical \\ City, Riyadh, Saudi Arabia; ${ }^{3}$ Oral and \\ Maxillofacial Department, Majmaah \\ University, Majmaah, Saudi Arabia; \\ ${ }^{4}$ Scientific Research Center, Prince Sultan \\ Military Medical City, Riyadh, Saudi \\ Arabia
}

Correspondence: Maha Ali Al Mohaya Oral Medicine and Special Care Dentistry, Prince Sultan Military Medical City, Riyadh, Saudi Arabia

Email malmohaya2013@gmail.com
Background: The coronavirus disease 2019 (COVID-19) pandemic necessitated widespread changes in delivery of dental care. Telemedicine utilization increased overnight during this pandemic because of its ability to enhance access to oral healthcare, easily link to remote area, time management, low cost, etc. We aimed to identify the utilization of telemedicine among oral medicine practitioners in Saudi Arabia during COVID-19 pandemic and identify future impacts, potential challenges and barriers hindering the implementation of telemedicine.

Methods: The present cross-sectional electronically self-administered supplement-based survey Supplement Based Survey study was conducted among different professional levels of oral medicine involving consultants, specialists, and residents. The supplement includes demographic data, the current use of telemedicine, participant's perspective on future implications, and potential barriers and limitations of telemedicine. Internal consistency was measured using Cronbach's alpha $(\alpha)$ to assess how closely related a set of items in our study.

Results: Of the total $(\mathrm{N}=75)$ oral healthcare professionals, $52 \%$ were male, $70.7 \%$ were Saudi, $45.3 \%$ were consultant, $42.7 \%$ had $1-5$ years of experience, $82.7 \%$ were practicing in urban areas, 93.3\% stated COVID-19 affected their clinics, consultation was the major reason for the use of telemedicine before (50.7\%) and during (72\%) COVID-19 outbreak, $57.3 \%$ were communicating with their patients, $97.33 \%$ had not experienced any cyber risk, and $45 \%$ patients were satisfied with the telemedicine service; our data showed a high level of homogeneity $(\alpha=0.82)$. The poor knowledge and training on telemedicine technologies may substantially $(p<0.05)$ impact the future implications of telemedicine in oral medicine practice.

Conclusion: Telemedicine could be a useful adjunct for oral medicine practice, especially for remote diagnosis, consultation, referral, training and education. Our study emphasizes an urgent need to increase the awareness and education on how to utilize and practice telemedicine technologies among medical staff to maximize the efficiency.

Keywords: awareness, barriers, COVID-19, oral medicine, telemedicine

\section{Introduction}

In December 2019, coronavirus disease (COVID-19) outbreak caused by SARSCoV-2 was detected in Wuhan, China. On the 11th of March 2020, the WHO announced and characterized the COVID-19 outbreak as a global pandemic. ${ }^{1}$ As a result of this outbreak, there was an increased demand in optimizing virtual health care systems across the globe. The dentists are at high risk of SARS-CoV-2 
infection because of their close contact with the patient's oral cavity, saliva, blood and respiratory tract secretions. ${ }^{2}$ Hence, the Kingdom of Saudi Arabia suspended regular dental treatments, allowing only emergency treatment. ${ }^{3}$ In the event of COVID-19 pandemic, telemedicine has been utilized in various specialties in dentistry as it provides an alternative approach for remote screening, diagnosis, consultation, treatment planning, and mentoring. ${ }^{4}$ Furthermore, this will reduce the load of patient's visit to the hospitals and, as a result, the risk of infection will be decreased. During such a pandemic, telemedicine can be an optimal alternative used in providing health care.

Telemedicine is defined as the use of advanced information technologies and electronic tool for communication to facilitate the clinical services even at remote area. Similar to telemedicine, teledentistry has emerged as a new tool with promising benefits for various dental disciplines including endodontics, orthodontics, oral surgery and pediatric dentistry. ${ }^{1,5}$ It holds the potential to improve access to and delivery of oral healthcare in rural and underserved areas. ${ }^{2,6}$ In addition, teledentistry has the potential to save resources and reduce the overall cost of healthcare. ${ }^{1}$ Estai et al have reported the implementation of teledentistry for screening of low caries risk children could save 40 million dollars per year in Australia. ${ }^{7}$ Oral lesions, such as ulcerative and potentially malignant lesions, can be difficult to diagnose in dentistry, particularly in underserved communities with limited access to specialized dental care. As a result, teledentistry may be able to fill this gap while also improving the quality of treatment. Conversely, several barriers, such as poor knowledge and training, lack of funding, absence of infrastructure such as connectivity, regulations of the telemedicine framework, patient's satisfaction, etc., have been reported as major hindrance in the implementation of telemedicine. ${ }^{6}$ Therefore, to overcome such barriers, an international legislation and collaboration with strategies may aid in the universal implementation of telemedicine.

A recent study conducted to assess acceptance of telemedicine by practicing physicians revealed most of the participants were having positive perceptions and willingness to apply telemedicine in their clinical practice. ${ }^{2,8}$ Many hospitals in Saudi Arabia have activated the virtual clinic via live video or phone call during the outbreak to minimize the unnecessary visits to hospitals. ${ }^{8,9}$ Hence, the present study aimed to assess the use of telemedicine among oral medicine practitioners in Saudi Arabia during COVID-19 pandemic. We further aimed to identify possible future impacts on oral medicine practice and to identify potential challenges and barriers hindering the implementation of telemedicine in the future practice of oral medicine specialty.

\section{Materials and Methods}

A cross-sectional survey study was carried out in Saudi Arabia to assess the use of telemedicine among oral medicine practitioners during the COVID-19 pandemic. The study was approved by the Institutional Review Board at Prince Sultan Military Medical City. Prior to data collection, study participants gave their informed, explicit consent to have their data published. An electronic self-administered supplement was designed and modified based on a previously published study. ${ }^{8}$ The supplement was revised by a telemedicine expert and was adopted in English language. Cronbach's alpha $(\alpha)$ was estimated for the entire supplement to assess how closely related a set of items in our study. The values of $\alpha$ may vary from 0 to 1 , with higher values indicating greater interconnectedness among test items. The supplement was submitted to study participants with different professional levels of oral medicine specialty involving consultants, specialists, and residents. The supplement is divided into four main sections including demographic data, the current use of telemedicine, potential barriers and limitations of telemedicine in the specialty practice and participant's perspective on future implications. Views on possible future implementation was measured using five-point Likert scale with $1=$ strongly agree, $2=$ agree, $3=$ neutral, $4=$ disagree, and $5=$ strongly disagree.

\section{Statistical Analysis}

The statistical analysis was carried out by using SSPS software, windows version 21.0 (Chicago, IL, USA). All parameters were expressed in frequencies and percentages. ANOVA test was conducted for the comparison of categorical data. Cronbach's alpha reliability method was used to estimate the internal consistency of data. The linear regression analysis was conducted to predict future implications, potential barriers and limitations of telemedicine. $p<0.05$ was considered as significant.

\section{Results}

In this present study, 75 participants were responded of which $52 \%$ were male and $48 \%$ were female, majority of the participants were Saudi (70.7\%), 48\% were within 2535 -year age group, followed by $36-45$ years (32\%) and 4655 years $(16 \%), 45.3 \%$ of the participants were consultant, 
$28 \%$ were specialist, $24 \%$ were resident and $2 \%$ were with $\mathrm{MSc} / \mathrm{PhD}$. The Majority of the participants (42.7\%) had 1-5 years of experience. In our study, the overall internal consistency $(\alpha)$ of the supplement was 0.82 , which is considered good. Most of the participants $(57.3 \%)$ were working in government university. The practice location of the participants was majorly in urban area (82.7\%) as shown in Table 1.

$93.3 \%$ of the participants had their clinics deferred due to COVID-19 pandemic. When the participants were asked for their perceptions about the usefulness of telemedicine in improving dental care, $65.3 \%$ were familiar, while

Table I Demographic and Professional Characteristics of Participants $(\mathrm{N}=75)$

\begin{tabular}{|c|c|c|}
\hline Characteristics & Number & Percentage \\
\hline \multicolumn{3}{|l|}{ Gender } \\
\hline Female & 39 & 52.0 \\
\hline Male & 36 & 48.0 \\
\hline \multicolumn{3}{|l|}{ Nationality } \\
\hline Non-Saudi & 22 & 29.3 \\
\hline Saudi & 53 & 70.7 \\
\hline \multicolumn{3}{|l|}{ Age group } \\
\hline$>55$ & 3 & 4.00 \\
\hline $25-35$ & 36 & 48.0 \\
\hline $36-45$ & 24 & 32.00 \\
\hline $46-55$ & 12 & 16.0 \\
\hline \multicolumn{3}{|l|}{ Professional level } \\
\hline Consultant & 34 & 45.3 \\
\hline MSc/ PhD student & 2 & 2.67 \\
\hline Resident & 18 & 24.0 \\
\hline Specialist & 21 & 28.0 \\
\hline \multicolumn{3}{|l|}{$\begin{array}{l}\text { Experience in oral medicine specialty } \\
\text { (year) }\end{array}$} \\
\hline$>15$ & 17 & 22.7 \\
\hline $\mathrm{I}-5$ & 32 & 42.7 \\
\hline $11-15$ & 8 & 10.7 \\
\hline $6-10$ & 18 & 24.0 \\
\hline \multicolumn{3}{|l|}{$\begin{array}{l}\text { To which health sector respondents } \\
\text { belong to }\end{array}$} \\
\hline Government hospital/clinic & 24 & 32.0 \\
\hline Governmental university & 43 & 57.3 \\
\hline Private hospital/clinic & 6 & 8.00 \\
\hline Private university & 2 & 2.67 \\
\hline \multicolumn{3}{|l|}{ The location of respondent's practice? } \\
\hline Major city & 62 & 82.7 \\
\hline Remote area & 1 & 1.33 \\
\hline Town & 12 & 16.00 \\
\hline
\end{tabular}

Abbreviation: N, number of participants.
$46.7 \%$ had used telemedicine before, and $28 \%$ of the participants stated that their practice setup supports the use of telemedicine, while $40 \%$ stated that their practice setup does not support the use of telemedicine. Consultation was the major reason for telemedicine use in oral medicine practice before $(50.7 \%)$ and during $(72 \%)$ COVID-19 pandemic. In the event of pandemic, $57.3 \%$ of the participants have been in communication with their patients via telemedicine and the majority of them preferred to use personal smartphone $(58.7 \%)$ to communicate with patients using WhatsApp application (62.7\%). Results revealed that only $27 \%$ of the participants have taken consent with their patients before telemedicine session. Poor image quality was one of the major reasons $(21.3 \%)$ for inconvenience in the use of telemedicine. Among the respondents, 97.3\% had not experienced any cyber risk while using telemedicine in their practice, $41.3 \%$ of the participants reported that the use of telemedicine is convenient, while $48 \%$ found it occasionally convenient; overall, $45 \%$ patients were satisfied with the telemedicine services (Table 2). When the comparison was made between experience levels to understand the future implications of telemedicine, it showed that future implications of telemedicine did not differ significantly among participants having different experience levels (Table 3). Similarly, when comparison was made between experience level with potential barriers and limitations of telemedicine in the oral medicine practice, only low levels of knowledge and training on telemedicine technology among medical staff were significantly associated with years of experience (Table 4).

A linear regression analysis was conducted to assess how the factors $\mathrm{C} 1, \mathrm{C} 2, \mathrm{C} 3, \mathrm{C} 4, \mathrm{C} 6, \mathrm{R} 3, \mathrm{R} 5$, and R6 significantly predicted with future implications of telemedicine $(\mathrm{F})$. We observed that one-unit increase in category "NO" of clinic deferred due to the COVID-19 pandemic (C1) decreased the value of F by 0.62 units, whereas oneunit increase in category 'YES' of conveniences of the use of telemedicine (R5) increased the value of $F$ by 0.45 units. Moreover, it was also found that one-unit increase in overall satisfaction of the patients (R6) by using telemedicine services decreased the value of $F$ by 0.53 units in R6 dissatisfied (Table 5). Linear regression analysis was also conducted to assess how these factors are associated with predicting potential barriers and limitations of telemedicine $(F)$ in the oral medicine practices. It was observed that one-unit increase in the conveniences of the use of telemedicine will decrease barriers and 
Table 2 Perceptions About the Usefulness of Telemedicine in Improving Dental Practice $(N=75)$

\begin{tabular}{|c|c|c|}
\hline Characteristics & Frequency & Percentage \\
\hline Was the clinic deferred due to the COVID-19 pandemic? (\% yes) & 70 & 93.3 \\
\hline \multicolumn{3}{|l|}{ How the respondents managed patients during COVID- 19 pandemic? } \\
\hline Patient rebooking & 35 & 46.7 \\
\hline Attending urgent cases only & 28 & 37.3 \\
\hline Communicating through telemedicine & 41 & 54.7 \\
\hline Are you familiar with the use of telemedicine? (Yes) & 49 & 65.3 \\
\hline \multicolumn{3}{|l|}{ Does respondents practice setup support the use of telemedicine? } \\
\hline I do not know & 24 & 32.0 \\
\hline No & 30 & 40.0 \\
\hline Yes & 21 & 28.0 \\
\hline Have ever utilized any form of telemedicine before the COVID-I9 pandemic? (\% yes) & 35 & 46.7 \\
\hline \multicolumn{3}{|l|}{ Please specify the reasons for telemedicine use in practice before COVID-19 pandemic? } \\
\hline Consultation & 38 & 50.7 \\
\hline Clinical discussion with colleagues & 33 & 44.0 \\
\hline Scheduled follow-up & 17 & 22.7 \\
\hline Diagnose new cases & 11 & 14.7 \\
\hline Medication refill & 15 & 20.0 \\
\hline Teaching & 21 & 28.0 \\
\hline \multicolumn{3}{|l|}{ Which media do respondents prefer to use when communicate through telemedicine? } \\
\hline Hospital devices & 12 & 16.0 \\
\hline Personal computer & 17 & 22.7 \\
\hline Personal smartphone & 44 & 58.7 \\
\hline Personal tablet & 2 & 2.67 \\
\hline Have you been in communication with patients via telemedicine during the COVID-19 pandemic? (\% yes) & 43 & 57.3 \\
\hline \multicolumn{3}{|l|}{ Which system/application were you using most to communicate with your patients? } \\
\hline Phone call & 30 & 40.0 \\
\hline WhatsApp & 47 & 62.7 \\
\hline Email & 4 & 5.33 \\
\hline Virtual videoconferencing & 5 & 6.67 \\
\hline \multicolumn{3}{|l|}{ What were the reasons for telemedicine use during the outbreak of COVID-19 pandemic? } \\
\hline Consultation & 54 & 72.0 \\
\hline Scheduled follow-up & 17 & 22.7 \\
\hline Diagnose new cases & 30 & 40.0 \\
\hline Medication refill & 20 & 26.7 \\
\hline Clinical discussion with colleague & 35 & 46.7 \\
\hline Teaching & 33 & 44.0 \\
\hline Have respondents ever experienced any cyber risk while using telemedicine in practice? (\% yes) & 2 & 2.67 \\
\hline \multicolumn{3}{|l|}{ Was it convenient to use telemedicine?: } \\
\hline No & 8 & 10.7 \\
\hline Occasionally & 36 & 48.0 \\
\hline Yes & 31 & 41.3 \\
\hline \multicolumn{3}{|l|}{ The reasons for inconvenience } \\
\hline Not familiar with the technology & 3 & 4.00 \\
\hline Poor internet Connection & 3 & 4.00 \\
\hline
\end{tabular}

(Continued) 
Table 2 (Continued).

\begin{tabular}{|c|c|c|}
\hline Characteristics & Frequency & Percentage \\
\hline Poor image quality & 16 & 21.3 \\
\hline Time consuming & 4 & 5.33 \\
\hline Patient dissatisfaction & 5 & 6.67 \\
\hline No proper set up & 4 & 5.33 \\
\hline \multicolumn{3}{|c|}{ Overall, how satisfied were the patients with the telemedicine services? } \\
\hline Dissatisfied & 4 & 5.33 \\
\hline I do not know & 37 & 49.3 \\
\hline Satisfied & 34 & 45.3 \\
\hline
\end{tabular}

Abbreviation: $\mathrm{N}$, number of participants.

limitations of telemedicine in the oral medicine by 0.32 (Table 6).

\section{Discussion}

Telemedicine is becoming a powerful tool in the healthcare system as it can increase the efficiency and accessibility of patient healthcare services, especially those in remote areas. ${ }^{8,9}$ Currently, demand for virtual health care system optimization has sharply increased worldwide for consultation, diagnosis and follow-up in different medical specialties. ${ }^{9,10}$ During the COVID-19 outbreak, many hospitals in Saudi Arabia activated virtual clinics via live video or phone calls to reduce unnecessary hospital visits. Likewise, many non-urgent appointments have been deferred, especially dental appointments, to minimize the risk of viral spread. Recently, the Ministry of Health of Saudi Arabia has established an e-health policy involving the use of telemedicine to increase accessibility and quality of treatment for patients and health care providers. To the best of our knowledge, this is the first study that aims to access the use of telemedicine among oral medicine practitioners in Saudi Arabia.

In the present study, among all respondents, $45.3 \%$ were consultants and $42.7 \%$ were having $1-5$ years of experience in practicing the specialty. The vast majority of participants work in the academic sector $(57.3 \%)$ of government universities as compared to clinicians employed in government hospitals (32\%) as shown in Table 1. Our finding is supported by evidence that oral medicine specialty is slowly emerging in Saudi Arabia and the establishment of a local residency program in 2017 will impact the growth and popularity in the near future. In the present study, the majority of the oral medicine practitioners $(82.7 \%)$ are located in major cities (Table 2).
Despite the tremendous growth of dentistry in Saudi Arabia, specialists are still mostly located in the major cities and towns. ${ }^{11}$ Therefore, this in fact highlights the importance of utilizing telemedicine to provide healthcare services for areas with limited accessibility to oral medicine practitioner. The reliability of telemedicine in the screening of oral diseases has shown its importance, especially for large populations in rural areas, as it is a costeffective screening method and enhances patient access to oral health services. ${ }^{12}$ Kruse et al recommended that the policy making should be applied in order to use telemedicine to particularly those in rural area. ${ }^{13}$ Other studies also recommended a protocol to diagnose a new case, consultation and follow-up in oral medicine practice, especially for patients in rural area and compromised patient whom under care. ${ }^{8,12,14}$

In our study, $93.3 \%$ of respondents' clinics deferred due to COVID-19 outbreak. More than half (54.7\%) of respondents were communicating through telemedicine with their patients in comparison to $46.7 \%$ of whom ever utilized any form of telemedicine before COVID-19 pandemic. The consultation (50.7\%) and clinical discussion (44\%) with colleagues are being the most common reason for the use of telemedicine in oral health practice before this pandemic. Similarly, in the event of COVID-19, we observed that majority of participants believe telemedicine can be used for consultation (72\%) and follow-up (Table 2), as observed in previous studies. ${ }^{15,16}$ More than half of the respondents were familiar with the use of telemedicine. The use of personal smartphones was the preferred method for sharing patient's images, radiograph and other telecommunications. The simplicity and userfriendliness of today's smartphones are the primary reasons for this practice. In contrast to encrypted emails, the 


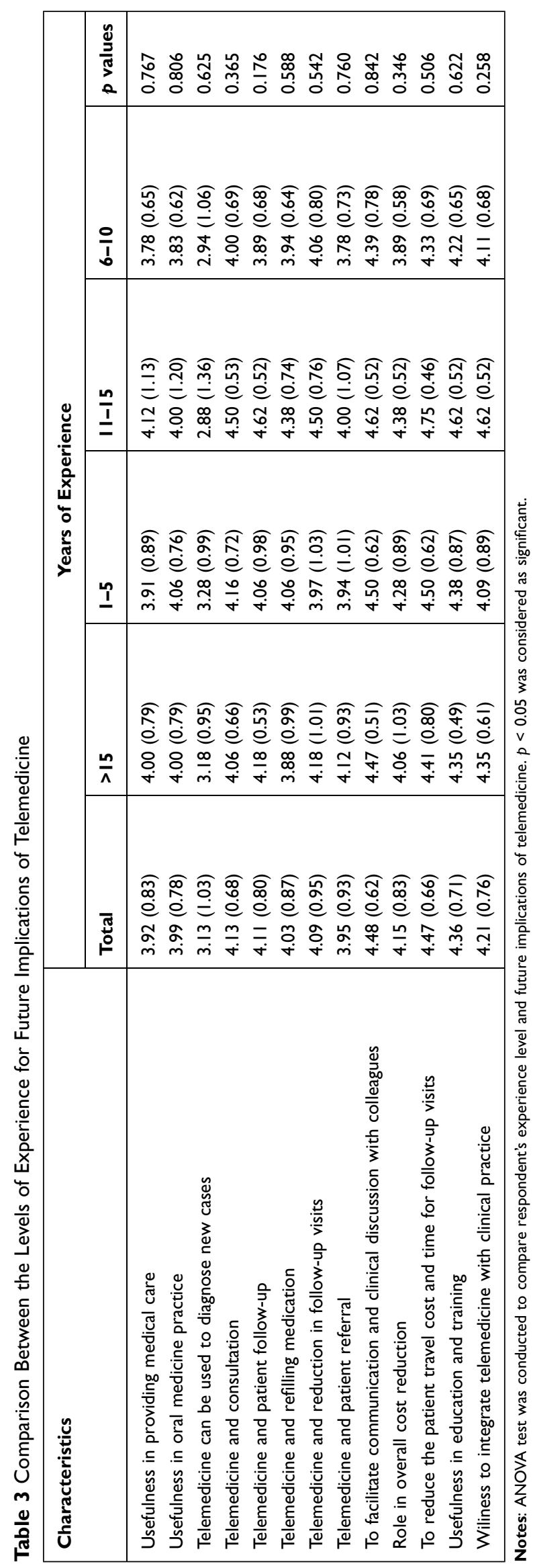




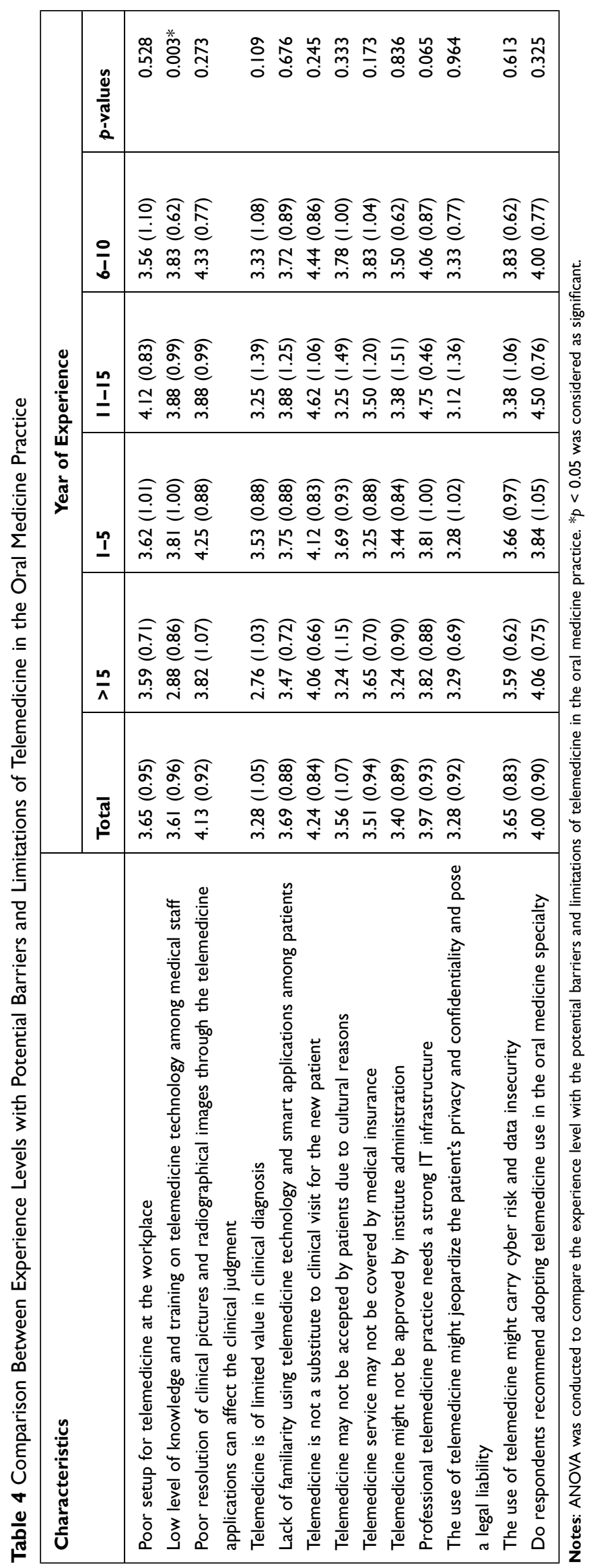


Table 5 Prediction of Future Implications of Telemedicine in Oral Health Practice

\begin{tabular}{|c|c|c|c|c|c|c|}
\hline Variable & B & $S E$ & $95 \% \mathrm{Cl}$ & $\boldsymbol{\beta}$ & $T$ & $\boldsymbol{p}$ values \\
\hline (Intercept) & 3.88 & 0.18 & $3.53-4.24$ & 0.00 & 21.72 & $0.001 *$ \\
\hline $\mathrm{Cl} \mathrm{No}$ & -0.62 & 0.22 & $-1.06-0.18$ & -0.28 & -2.84 & $0.006 *$ \\
\hline C2 Yes & 0.14 & 0.14 & $-0.13-0.4 \mid$ & 0.12 & 1.01 & 0.317 \\
\hline C3 Yes & 0.13 & 0.17 & $-0.20-0.46$ & 0.11 & 0.79 & 0.434 \\
\hline C3 No & -0.03 & 0.14 & $-0.3 \mid-0.25$ & -0.03 & -0.20 & $0.84 I$ \\
\hline C4 No & -0.02 & 0.13 & $-0.29-0.25$ & -0.02 & -0.15 & 0.881 \\
\hline C6 Yes & -0.28 & 0.15 & $-0.59-0.03$ & -0.25 & -1.83 & 0.072 \\
\hline R3 Yes & 0.17 & 0.12 & $-0.07-0.4 I$ & 0.14 & 1.44 & 0.156 \\
\hline R5 Yes & 0.45 & 0.12 & $0.22-0.69$ & 0.41 & 3.83 & $0.001 *$ \\
\hline R5 No & -0.07 & 0.20 & $-0.46-0.32$ & -0.04 & -0.35 & 0.731 \\
\hline R6 satisfied & 0.21 & 0.13 & $-0.05-0.48$ & 0.19 & 1.62 & 0.109 \\
\hline R6 dissatisfied & -0.53 & 0.26 & $-1.05-0.02$ & -0.22 & -2.07 & $0.042^{*}$ \\
\hline
\end{tabular}

Notes: A linear regression analysis was conducted to assess how the factors $\mathrm{Cl}, \mathrm{C2}, \mathrm{C} 3, \mathrm{C} 4, \mathrm{C} 6, \mathrm{R} 3$, R5, and R6 significantly predicted future implications of telemedicine (F). ${ }^{*} p<0.05$ was considered as significant. $\mathrm{Cl}=$ "Was clinic deferred due to the COVID-19 pandemic?", C2 = "Familiarity with the use of telemedicine?", C3 = "Does practice setup support the use of telemedicine?", C4 = "Have the respondent ever utilized any form of telemedicine before the COVID-19 pandemic?", C6 = "Have the respondent been in communication with patients via telemedicine during the COVID-19 pandemic?", R3 = "Do the consent of patients was taken before telemedicine session?", R5 = "Was it convenient to use telemedicine?", R6 = "Overall, how satisfied were the patients with the telemedicine services?".

Table 6 Identification of Potential Barriers and Limitations of Telemedicine in the Oral Health Practice

\begin{tabular}{|c|c|c|c|c|c|c|}
\hline Variable & B & $S E$ & $95 \% \mathrm{Cl}$ & $\boldsymbol{\beta}$ & $T$ & $p$ values \\
\hline Intercept & 4.05 & 0.17 & $3.70-4.39$ & 0.00 & 23.63 & $0.001 *$ \\
\hline CINo & 0.18 & 0.21 & $-0.24-0.60$ & 0.10 & 0.84 & 0.401 \\
\hline C2Yes & -0.08 & 0.13 & $-0.34-0.18$ & -0.09 & -0.60 & 0.552 \\
\hline C3Yes & -0.02 & 0.16 & $-0.34-0.30$ & -0.02 & -0.11 & 0.913 \\
\hline $\mathrm{C} 3 \mathrm{No}$ & 0.16 & 0.13 & $-0.11-0.43$ & 0.18 & 1.20 & 0.234 \\
\hline C4No & -0.25 & 0.13 & $-0.50-0.01$ & -0.28 & -1.91 & 0.060 \\
\hline C6Yes & -0.19 & 0.15 & $-0.48-0.10$ & -0.22 & -1.30 & 0.198 \\
\hline R3Yes & 0.02 & 0.11 & $-0.21-0.25$ & 0.02 & 0.15 & 0.881 \\
\hline R5Yes & -0.32 & 0.11 & $-0.55-0.10$ & -0.37 & -2.87 & $0.006 *$ \\
\hline R5No & -0.19 & 0.19 & $-0.56-0.19$ & -0.13 & -1.00 & 0.321 \\
\hline R6 satisfied & 0.03 & 0.13 & $-0.22-0.28$ & 0.03 & 0.22 & 0.829 \\
\hline R6 dissatisfied & 0.03 & 0.25 & $-0.47-0.52$ & 0.01 & 0.10 & 0.917 \\
\hline
\end{tabular}

Notes: A linear regression analysis was conducted to assess how the factors Cl, C2, C3, C4, C6, R3, R5, and R6 significantly predicted F (future implications of telemedicine). $* p<0.05$ was considered as significant. $\mathrm{Cl}=$ "Was clinic deferred due to the COVID-I9 pandemic?", $\mathrm{C} 2=$ "Are the respondent were familiar with the use of telemedicine?", C3= "Does practice setup support the use of telemedicine?", C4 = "Have respondent ever utilized any form of telemedicine before the COVID-19 pandemic?", C6 = "Have respondent been in communication with patients via telemedicine during the COVID-I9 pandemic?", R3 = " Do the consent of patients was taken before telemedicine session?", R5 = "Was it convenient to use telemedicine?", R6 = "Overall, how satisfied were the patients with the telemedicine services?".

patient's privacy is compromised while exchanging the information through smartphone applications. The communication with patients through WhatsApp was the most common (62.7\%) application during pandemic (Table 2) and encrypted to dissipate the public privacy concerns. Thus, while using mobile phones to exchange patient-related materials, all health care providers are expected to understand the value of data privacy. ${ }^{17-19}$ Among participants, $40 \%$ of them states that their practice setup does not support the use of telemedicine, which may give an idea that telemedicine needs to be more accessible and utilized within hospital settings. However, with the outbreak of COVID-19, in a large number of medical specialties, several hospitals have launched virtual clinics. Such crisis has rapidly implemented the use of telemedicine across the globe. The majority of the participants $(97.3 \%)$ have not experienced any sort of cyber risk. However, with the current routine information technology, there is a risk concerning in patient information confidentiality. ${ }^{20}$ In our study, $21.3 \%$ participants believe that telemedicine is not convenient due to poor image quality (Table 2). In contrast to our finding, Petruzzi and 
De Benedittis have found that $93 \%$ of photos were of good quality and only $7 \%$ were considered as poor. ${ }^{21}$

Almost half of the participants were not aware about patient's satisfaction with telemedicine service. According to Bradley et al paper, almost $90 \%$ of patients were satisfied with the telemedicine system. ${ }^{22}$

In our study, we did not observe any significant impact of the respondent's experience level on future implications of telemedicine (Table 3); however, poor knowledge and training on telemedicine technology among medical staff were significantly associated with years of experience (Table 4). It may be considered as potential barriers and limitations of telemedicine in the oral medicine practice.

When we analyzed the impact of convenience of telemedicine on future implication and barriers of telemedicine, our results showed that convenience of telemedicine is significantly associated with implication and barriers of telemedicine (Table 5). Additionally, dissatisfaction of the patients with telemedicine significantly decreases the possibility of future implications of telemedicine in oral medicine practice (Table 6). Most of the respondents were willing to integrate telemedicine into their clinical practice. However, the technological barriers and lack of computer literacy prevailed as serious challenges in the successful implementation of telemedicine. The previous studies from Saudi Arabia reported that non-familiarity of technical staff, poor design, privacy, cost of table equipment, lack of training, problems with information and communication technology are major obstacles to the adoption of telemedicine. ${ }^{17,23}$ Similarly, the same obstacles to telemedicine were identified by the Centers for Disease Control and Prevention (CDC) during COVID-19. ${ }^{24}$

In concordance with our results, previous studies have demonstrated that poor knowledge and awareness of telemedicine was a major hindrance to the implementation of telemedicine. ${ }^{25-27}$ Other barriers in the present study are poor resolution of clinical pictures that might affect the clinical judgment, cultural acceptance, privacy, confidentiality and legal liability. A study by Villa et al found almost one third of total providers believe that images were not sufficient to make a diagnosis. ${ }^{19,22}$

Currently, with the COVID-19 pandemic, medical insurance in the United States of America is providing reimbursements for telemedicine virtual clinics conducted for both the inpatient and outpatient. ${ }^{19}$ In Saudi Arabia, the Council of Cooperative Health Insurance approved healthcare policy that covers telemedicine services until the end of year 2021. This represents the importance of implementing telemedicine within the health insurance companies for future plans and health care coverage. ${ }^{28}$

The majority of the participants $(92 \%)$ agree that telemedicine can be a useful tool for education and training purposes. Interestingly, we also found that $23 \%$ of the respondents were using telemedicine for teaching purposes during COVID-19 pandemic as it was proven in previous study that telemedicine can provide an addition to the conventional teaching methods in dental education. ${ }^{15}$ In contrast, majority of the participants $(82.6 \%)$ believe that telemedicine is not a substitute for face-to-face clinical visits. However, most of the participants are willing to adopt telemedicine as a part of their clinical practice. This outcome is in accordance with previous study where $95 \%$ of participants believed that telemedicine can be adopted in their clinical practice. ${ }^{23}$ The supplement was delivered to the study participants in English language; therefore, a preventive and not declared selection of the study participants was performed: as a consequence, we may guess that the eventual population included professionals more skilled, more up-to date in terms of modern technologies, with subsequent consequences in the significance of the collected data.

There are several limitations, such as small sample size, inaccuracy of database for the registered specialists, cultural concerns, cost-effectiveness and adequate infrastructure availability to practice telemedicine, that were not addressed. Therefore, future studies with larger sample size along with considering the above constraints are required to strengthen the present findings.

In conclusion, telemedicine might provide an efficient adjunct tool for oral medicine practice, especially for remote diagnosis, consultation, referral, training and education.

Rural areas with limited access can benefit from the use of telemedicine as the majority of oral medicine practitioners are located in major cities. We suggest to introduce telemedicine guidelines and license for the practitioner and also to provide the services for patients with limited accessibility to practice. Furthermore, our study emphasizes an urgent need to increase the awareness and training on how to utilize and practice telemedicine technologies among medical staff.

\section{Acknowledgments}

The authors gratefully acknowledge the Saudi Commission for Health for their support in distributing the supplement among registered oral medicine practitioners in Saudi Arabia. 


\section{Disclosure}

The authors report no conflicts of interest in this work.

\section{References}

1. World Health Organization. Coronavirus Disease (COVID-19) Pandemic [Internet]. World Health Organization; 2020.

2. Betancourt JA, Rosenberg MA, Zevallos A, Brown JR, Mileski M. The impact of COVID-19 on telemedicine utilization across multiple service lines in the United States. Healthcare (Basel). 2020;8(4):380. doi: $10.3390 /$ healthcare 8040380

3. Ministry of Health, Saudi Arabia; 2020. Available from: https://www. moh.gov.sa/Pages/Default.aspx. Accessed September 28, 2021.

4. Ghai S. Teledentistry during COVID-19 pandemic. Diabetes Metab Syndr. 2020;14(5):933-935. doi:10.1016/j.dsx.2020.06.029

5. World Health Organization. Global Diffusion of eHealth: Making Universal Health Coverage Achievable. Report of the Third Global Survey on eHealth. World Health Organization; 2016.

6. American Telemedicine Association. Telehealth basics. Available from: https://www.americantelemed.org/. Accessed September 28, 2021.

7. Estai M, Kanagasingam Y, Mehdizadeh M, et al. Teledentistry as a novel pathway to improve dental health in school children: a research protocol for a randomised controlled trial. BMC Oral Health. 2020;20(1). doi:10.1186/s12903-019-0992-1.

8. Albarrak AI, Mohammed R, Almarshoud N, et al. Assessment of physician's knowledge, perception and willingness of telemedicine in Riyadh region, Saudi Arabia. J Infect Public Health. 2021;14 (1):97-102. doi:10.1016/j.jiph.2019.04.006

9. Webster P. Virtual health care in the era of COVID-19. Lancet. 2020;395(10231):1180-1181. doi:10.1016/S0140-6736(20)30818-7

10. Calton B, Abedini N, Fratkin M. Telemedicine in the time of Coronavirus. J Pain Symptom Manage. 2020;60(1):e12-e14. doi:10.1016/j.jpainsymman.2020.03.019

11. Al Shammery A. Dentistry in Saudi Arabia and the challenges of Vision 2030. Saudi J Oral Sci. 2016;3(2):59. doi:10.4103/16586816.188080

12. Pentapati KC, Mishra P, Damania M, Narayanan S, Sachdeva G, Bhalla G. Reliability of intra-oral camera using teledentistry in screening of oral diseases - a pilot study. Saudi Dent J. 2017;29 (2):74-77. doi:10.1016/j.sdentj.2017.03.002

13. Kruse CS, Williams K, Bohls J, Shamsi W. Telemedicine and health policy: a systematic review. Health Policy Technol. 2021;10 (1):209-229. doi:10.1016/j.hlpt.2020.10.006

14. Kichloo A, Albosta M, Dettloff K, et al. Telemedicine, the current COVID-19 pandemic and the future: a narrative review and perspectives moving forward in the USA. Fam Med Community Health. 2020;8(3):e000530. doi:10.1136/fmch-2020-000530
15. Almazrooa SA, Mansour GA, Alhamed SA, et al. The application of teledentistry for Saudi patients' care: a national survey study. J Dent Sci. 2021;16(1):280-286. doi:10.1016/j.jds.2020.04.014

16. Silva BM, Rodrigues JJ, de la Torre Díez I, López-Coronado M, Saleem K. Mobile-health: a review of current state in 2015. J Biomed Inform. 2015;56:265-272. doi:10.1016/j.jbi.2015.06.003

17. Scott Kruse C, Karem P, Shifflett K, Vegi L, Ravi K, Brooks M. Evaluating barriers to adopting telemedicine worldwide: a systematic review. J Telemed Telecare. 2016;24(1):4-12. doi:10.1177/1357633 X16674087

18. Liu X, Sutton PR, McKenna R, et al. Evaluation of secure messaging applications for a health care system: a case study. Appl Clin Inform. 2019;10(1):140-150. doi:10.1055/s-0039-1678607

19. Villa A, Sankar V, Shiboski C. Tele(oral)medicine: a new approach during the COVID-19 crisis. Oral Dis. 2021;27(Suppl 3):744-745. doi:10.1111/odi.13364

20. Chen JW, Hobdell MH, Dunn K, Johnson KA, Zhang J. Teledentistry and its use in dental education. J Am Dent Assoc. 2003;134 (3):342-346. doi:10.14219/jada.archive.2003.0164

21. Petruzzi M, De Benedittis M. WhatsApp: a telemedicine platform for facilitating remote oral medicine consultation and improving clinical examinations. Oral Surg Oral Med Oral Pathol Oral Radiol. 2016;121(3):248-254. doi:10.1016/j.oooo.2015.11.005

22. Bradley M, Black P, Noble S, Thompson R, Lamey PJ. Application of teledentistry in oral medicine in a Community Dental Service, N. Ireland. Br Dent J. 2010;209(8):399-404. doi:10.1038/sj.bdj.2010. 928

23. El-Mahalli A, El-Khafif S, Al-Qahtani M. Successes and challenges in the implementation and application of telemedicine in the eastern province of Saudi Arabia. Perspect Health Inf Manag. 2012;9:1-27.

24. Centers for Disease Control and Prevention. Uses of Telehealth during COVID-19 in Low Resource Non-U.S. Settings. Available from: https://www.cdc.gov/coronavirus/2019-ncov/globalcovid-19/tele health-covid19-nonUS.html. Accessed October 18, 2021.

25. Shahpori R, Hebert M, Kushniruk A, Zuege D. Telemedicine in the intensive care unit environment - a survey of the attitudes and perspectives of critical care clinicians. J Crit Care. 2011;26(3):328. e9-15. doi:10.1016/j.jcrc.2010.07.013

26. Demartines N, Freiermuth O, Mutter D, Heberer M, Harder F. Knowledge and acceptance of telemedicine in surgery: a survey. $J$ Telemed Telecare. 2000;6(3):125-131. doi:10.1258/135763300 1935167

27. Zayapragassarazan Z, Kumar S. Awareness, knowledge, attitude and skills of telemedicine among health professional faculty working in teaching hospitals. J Clin Diagn Res. 2016;10(3):JC01-JC04.

28. Council of Cooperative Health Insurance. Available from: https:// www.cchi.gov.sa. Accessed October 18, 2021.
Risk Management and Healthcare Policy

\section{Publish your work in this journal}

Risk Management and Healthcare Policy is an international, peerreviewed, open access journal focusing on all aspects of public health, policy, and preventative measures to promote good health and improve morbidity and mortality in the population. The journal welcomes submitted papers covering original research, basic science, clinical \& epidemiological studies, reviews and evaluations, guidelines, expert opinion and commentary, case reports and extended reports. The manuscript management system is completely online and includes a very quick and fair peer-review system, which is all easy to use. Visit http://www.dovepress.com/testimonials.php to read real quotes from published authors. 